\title{
HISTORY OF UTILIZATION OF THE COMPUTATIONAL FLUID DYNAMICS METHOD FOR STUDY PICO HYDRO TYPE CROSS-FLOW
}

\author{
DENDY ADANTA ${ }^{1}$, DEWI PUSPITA SARI ${ }^{2 *}$, \\ NURA MUAZ MUHAMMAD ${ }^{3}$, AJI PUTRO PRAKOSO ${ }^{4}$ \\ ${ }^{I}$ Departement of Mechanical Engineering, Faculty of Engineering, Universitas Sriwijaya, Palembang \\ - South Sumatera, Indonesia \\ ${ }^{2}$ Study Program of Mechanical Engineering Education, Faculty of Education, Universitas Sriwijaya, \\ Palembang - South Sumatera, Indonesia \\ ${ }^{3}$ Faculty of Engineering, Kano University of Science anf Technology, Wudil, Nigeria \\ ${ }^{4}$ Departement of Mechanical Engineering, Faculty of Manufacturing Technology, Universitas Jendral \\ Ahmad Yani, Cimahi - West Java, Indonesia \\ *Corresponding author: dewipuspita@fkip.unsri.ac.id
}

(Received: 15 January 2021; Accepted: 21 February 2021; Published on-line: 03 March 2021)

\begin{abstract}
Energy crisis in particular, electricity in the isolated rural areas of Indonesia is a very crucial issue that needs to be resolve through electrification . Compared to other options, pico hydro cross-flow turbine (CFT) is the better option to provides electrical power for the isolated rural areas. Studies to improve CFT performance can be undertaken analytically, numerically, experimentally, or a combination of those methods. However, the development of computer technology makes numerical simulation studies have become increasingly frequent. This paper describes the utilization of the computational fluid dynamic (CFD) approach in the pico hydro CFT method. This review has resulted that the recommended Renormalization Group (RNG) k- $\varepsilon$ turbulence model for CFT CFD simulation because its absolute relative error is lower than standard k- $\varepsilon$ and transitional Shear Stress Transport (SST). The absolute relative error for the RNG k- $\varepsilon$ turbulence model of $3.08 \%$, standard k- $\varepsilon$ of $3.19 \%$, and transitional SST of $3.10 \%$. While for the unsteady approach, the six-degrees of freedom (6-DoF) are considered because more accurate than moving mesh. The absolute relative error for 6-DoF of $3.1 \%$ and moving mesh of $9.5 \%$. Thus, based on the review, the RNG k- $\varepsilon$ turbulence model and 6-DoF are proposed for the pico hydro CFT CFD study.
\end{abstract}

KEYWORDS: Pico hydro; Crossflow turbine; CFD; RANS; 6-DoF approach

\section{INTRODUCTION}

The cross-flow turbine (CFT) is categorized as an impulse turbine where it dominates the kinetic energy of water through the blade to rotate the shaft [1][2]. The CFT absorbs water energy in two-steps: first stage and second stage [3]. The two-step energy transfer in the CFT makes this turbine very interesting to be studied, especially about its flow field such as turbulence phenomena [4][5]. By understanding the flow field, flow losses that occur in the CFT can be minimized so that efficiency can be increased [6][3] [7][8][9][10][11].

Studies to improve CFT performance can be undertaken analytically, numerically, experimentally, or a combination of those methods. Furthermore, the development of computer technology makes numerical simulation studies have become increasingly frequent [12][5]. 
Fluid flow characteristic inside the CFT's nozzle has been successfully obtained using the numerical method in 1985 [8] and some optimum parameters of CFT's nozzle design wererecommended. Furthermore, this study also confirmed the optimum angle of attack recommendation [7][13]. The study about CFT's nozzle has been conducted where recommend that numerical analysis is very promising to be used for investigation of nozzle design with better pressure distributions [14]. Those both studies were conducted using a one-dimension numerical approach.

At the beginning of the twenty-first century, some computational fluid dynamics (CFD) softwares were developed and allowed the researchers to investigate more complex fluid flow in a more affordable method [15]. Some two or three dimensional (2 or 3D), steady-state or transient analysis about CFT has been conducted in this period [10][11][16][17][9]. In 2008, a series of numerical simulations using a quasi 2D steady-state approach has been conducted to find the most efficient guide vane opening angle in commercial CFT and investigate its internal flow characteristic [16]. A deeper investigation at the internal flow of CFT has been conducted in 2011, and then found the influence of shaft inside CFT [17]. Some losses cause also found in CFT's hydrodynamic flow using 2D transient CFD simulations [17]. In 2013, several studies about CFT have been conducted which started by finding the optimum design of CFT using extensive literature review combined with some quasi 2D and 3D transient simulations [9]. The optimum results then validated and sharpened in several later studies [18][19]. The 3D steadystate numerical study has been conducted and successfully improve the CFT performance by modifying its nozzle curvature [10]. Another CFT's nozzle improvement has found the $90 \%$ of efficiency CFT by using numerical simulations validated by experimental testing[11][20]. Currently, their study was trying to improve CFT efficiency by doubling its nozzle [21].

Nowadays, the numerical simulations of CFT were becoming more complex due to the need of getting more accurate results. By using rigid body options inside six degrees of freedom (6-DOF) approach, the turbine movement can be obtained as the results of the numerical calculation. Several current studies have been carried out using this option to obtain deeper investigation or make some breakthrough improvements to CFT design [6][22][23]. A study in 2018 using a 6-DoF dynamic meshing approach to find the effect of airfoil profile on the internal flow characteristic and the turbine's performance by comparing three cases of CFT [6]. That study's result concluded that the airfoil profile might give a positive effect on the fluid flow characteristic inside the turbine, but, not for its performance. There was because the impulse effect in CFT is more dominant than the reaction effect [6]. Furthermore, at the same time, another study examined the effect of blade curvature depth to its performance [22], then the other simplifies the design calculation formula into ratio to the outer diameter [23].

Many studies on CFT use CFD, the present study tried to summarize CFT development, especially using a numerical approach. This study reviewing some studies that related to CFD results quality on simulating pico hydro CFT. It aims to recommend the suitable unsteady approach and turbulence model of CFT with a pico scale for CFD numerical simulation.

\section{OVERVIEW OF CFT STUDY BEFORE TWENTY-FIRST CENTURY}

CFT was firstly introduced by A. Michell in 1903 then it's first theoretical approach is found by D. Banki, and then improved by Sonnek in 1923 [24]. Mockmore and Merryfield [3] found that CFT's optimum US specific speed was 14, higher than another impulse turbine. The results also found that the CFT has stable performance under fluctuating water discharge [3]. Haimerl [25] found that the pressure at the tip of CFT's nozzle was not zero, this makes this turbine referred as not purely an impulse turbine. 
Nakase (1982) [26] has reviewed the effect of CFT's nozzle shape and size to its performance. He recommended a ratio between CFT's nozzle's height and width based on Equation 1 as follows:

$$
\frac{s_{m}}{R \lambda} \cong 0.26
$$

where, $\mathrm{S}_{0}$ is the nozzle's initial height, $\mathrm{R}$ is the outer radius of CFT, and $\lambda$ is the nozzle's discharge angle. The recommendation was tested and improve CFT performance, where the efficiency of the CFT can reach 82\% [26]. Then, Durgin and Fay (1984) [27] found that the first stage energy transfer gave a higher contribution to CFT performance for about $83 \%$ of total energy transfer. This finding is still relevant nowadays [16]. Continued prior study about CFT's nozzle [26], a study conducted in 1985 [8]. Fukutomi et al. (1985) [8] concluded that the numerical approach is an appropriate alternative to improve on the CFT's nozzle. Continue to use a numerical approach, Fukutomi et al. (1991) [28] investigated the flow field of CFT [28]. Fukutomi et al. (1991) [28] found the effect of the diameter ratio on the CFT performance.

Khosrowpanah et al. (1988) [24] found that the optimum $\lambda$ for CFT was $90^{\circ}$ and still used until now. Then, Khosrowpanah et al. (1993) [7] and (1994) [13] concluded that the optimum angle of attack $(\alpha)$ for CFT was $22^{\circ}$, which is valid until now [29]. Aziz and Totapally (1994) [13] validates the Mockmore and Merryfield [3] propose of the optimum diameter ratio (d/D) of 0.68 .

The major finding of CFT studies conducted before the $21^{\text {st }}$ century was related to the main design parameter of CFT. Table 1 summarises the parameters considered in the studies conducted before the $21^{\text {st }}$ century.

Table 1: The CFT studies from 1949 until 1994

\begin{tabular}{lcccccc}
\hline \multicolumn{1}{c}{ Authors } & Year & $\boldsymbol{\alpha}$ & $\begin{array}{c}\text { Nozzle } \\
\text { design }\end{array}$ & $\boldsymbol{\lambda}$ & $\mathbf{d} / \mathbf{D}$ & $\mathbf{N}_{\mathbf{b}}$ \\
\hline Mockmore and Merryfield [3] & 1949 & $\checkmark$ & $\checkmark$ & & $\checkmark$ & $\checkmark$ \\
Haimerl [25] & 1960 & & $\checkmark$ & & & $\checkmark$ \\
Nakase [26] & 1982 & & $\checkmark$ & $\checkmark$ & & \\
Durgin and Fay [27] & 1984 & & & & $\checkmark$ & \\
Fukutomi et al. [8] & 1985 & & $\checkmark$ & & & \\
Khosrowpanah et al. [24] & 1988 & & & $\checkmark$ & & \\
Fukutomi et al. [28] & 1992 & & & $\checkmark$ & $\checkmark$ & $\checkmark$ \\
Aziz [13] & 1994 & $\checkmark$ & & $\checkmark$ & $\checkmark$ \\
\hline
\end{tabular}

\section{CFT STUDY IN THE TWENTY-FIRST CENTURY}

At the beginning of the $21^{\text {st }}$ century, almost all CFT studies used CFD simulation. The CFD is widely used because it is cheap, fast, and able to visualize the flow field in detail [30]. Kaniecki (2002) [25] trying to improve CFT performance by adding a draft tube at the outflow and analyzing the flow characteristic at the draft tube. Kaniecki and Steller (2003) [4] performed several CFD simulations to analyze the flow pattern of CFT and classify CFT as a reaction turbine. Choi et al. (2006) [31] investigated the effect of blade angle to the internal flow characteristic, which recommends that the optimum blade outlet angle $\left(\beta_{2}\right)$ is $90^{\circ}$. Choi et al. (2007) [32] investigated internal flow with the variation of nozzle shape and found that CFT has both impulse and reaction turbine characteristics. Choi et al. (2008) [16] have found that the internal flow characteristic has a high influence on CFT performance. A study about internal flow characteristics with the variation of turbine angular velocity has been conducted 
[17]. Andrade et al. (2011) [17] concluded that the recirculation flow that occurs as a shock where this flow should be minimized so that the turbine can work properly.

The CFT optimization using the CFD method has been conducted by Sammartano et al. [33] in 2014. They developedCFT nozzles that can be adjusted for fluctuating discharge conditions. A year later, Sammartano et al. [34] tried to utilize CFT to produce electricity and flow regulators outright for the water conveyance system. In 2016, Sammartano et al. [19] validated the optimization which conducted in 2013 [9], also proposed a formula to correct inlet velocity. the study also compared some turbulence models to the experimental results to ensure the right turbulent model for the CFT case.

Some studies utilize the CFD method to improve CFT performance. Acharya (2015) [10] redesigned the CFT nozzle to improve its performance. The re-design of the CFT nozzle has significantly increased its efficiency from $63.7 \%$ to $76.6 \%$ [10].

Several studies conducted to obtain high efficient CFT started to improve the tip of the nozzle by Adhikari and Wood (2017) [11]. Furthermore, Adhikari and Wood (2018) [20] using the CFD method investigated flow pattern and turbine performance when CFT run under the part-load condition which resulting in more efficient water discharge control of CFT. And, Adhikari and Wood (2018) [21] investigated CFT with a double nozzle to attain more efficiency. At the end of 2018, a summary of prior studies been made into a review paper related to the effort of several studies to attain the high efficiency of CFT [29]. The obtained maximum efficiency of several studies in the $21^{\text {st }}$ century is briefly mentioned in Table 2 .

Table 2: Maximum attained CFT efficiency from several current studies

\begin{tabular}{lcc}
\hline \multicolumn{1}{c}{ Authors } & $\begin{array}{c}\text { Numerical } \\
\text { efficiency }\end{array}$ & $\begin{array}{c}\text { Experiment } \\
\text { efficiency }\end{array}$ \\
\hline Kaniecky, et.al. (2002-2003) [25][4] & $74,3 \%$ & $78,6 \%$ \\
Choi, et.al. (2006-2008) [31][32][16] & $65,7 \%$ & $76,2 \%$ \\
$\begin{array}{l}\text { De Andrade, et.al. (2011) [17] } \\
\text { Sammartano, } \quad \text { et.al. }\end{array}$ & $76 \%$ & $72 \%$ \\
[9][33][34][19] & & \\
Acharya, et.al. (2015) [10] & $79,4 \%$ & $80,6 \%$ \\
Chichkhede, et.al. (2016) [2] & $76,6 \%$ & - \\
Adhikari, et.al. (2017-2018) [11][20][21] & $88 \%$ & - \\
\hline
\end{tabular}

All the CFD simulation study in Table 2 has been conducted under the 3D domain. However, in 2018 [6], 2D CFD analysis has been used to improve CFT performance by modifying the turbine blade with airfoil profile and found some turbulence characteristics at the internal flow of CFT which influence its performance. And, 2D CFD study used [22] to investigate the modification effect of the blade curve to its performance.

\section{EFFECT OF TURBULENCE MODEL IN PICO HYDRO CFT NUMERICAL SIMULATION}

A comparison of three turbulent models of $k-\varepsilon$ model, RNG $k-\varepsilon$ model, and Transitional SST was conducted to determine their effects on computational results (predictions) [19]. The comparison results are briefly explained in Table 3. From Table 3, the $k-\varepsilon$ and RNG $k-\varepsilon$ model has higher average relative error $\left(\delta_{R}\right)$ than SST model [19]. The relative error is defined by Equation 2 [19]. 


$$
\delta_{R}=\frac{\eta_{\sin }-\eta_{\exp }}{\eta_{\exp }}
$$

and the absolute relative error $\left(\delta_{R A}\right)$ is defined using Equation 3.

$$
\delta_{R A}=\frac{\left|\eta_{\operatorname{sim}}-\eta_{\exp }\right|}{\eta_{\exp }}
$$

where, $\eta_{\exp }$ is experimental turbine efficiency and $\eta_{\text {sim }}$ is CFD simulation turbine efficiency result. This study has conducted in a $3 \mathrm{D}$ domain which meant has more wall than $2 \mathrm{D}$ simulation, where turbulence model of $k-\varepsilon$ with the near-wall treatment has a small weakness than $k-\varepsilon$ standard.

Table 3: The CFD results in a relative error from experimental in various turbulence model by Sammartano, et al. [19]

\begin{tabular}{cccc}
\hline $\mathbf{V}_{\mathbf{t}} / \mathbf{U}$ & $\boldsymbol{k}-\boldsymbol{\varepsilon}$ & RNG $\boldsymbol{k}-\boldsymbol{\varepsilon}$ & Transitional SST \\
\hline 1,2 & $-2,52 \%$ & $-1,56 \%$ & $0,05 \%$ \\
1,4 & $-3,56 \%$ & $-3,07 \%$ & $-1,15 \%$ \\
1,6 & $-3,95 \%$ & $-2,83 \%$ & $-1,16 \%$ \\
1,8 & $-5,45 \%$ & $-3,20 \%$ & $-0,96 \%$ \\
2,0 & $-5,93 \%$ & $-3,37 \%$ & $-1,55 \%$ \\
2,2 & $-2,07 \%$ & $0,07 \%$ & $0,58 \%$ \\
$\delta_{\mathrm{R}}$ & $-3,91 \%$ & $-2,39 \%$ & $-0,70 \%$ \\
$\delta_{\mathrm{RA}}$ & $3,91 \%$ & $2,41 \%$ & $0,91 \%$ \\
\hline
\end{tabular}

Verification of studies conducted by Sammartano, et.al. [19] by Siswantara et.al [5]. The difference between Siswantara et.al. [5] with Sammartano, et.al. [19] is a simplification of the model, where Siswantara et.al. [5] uses a 2D model while Sammartano, et.al. [19] used a 3D model. In addition to verifying that there is an influence on the use of the turbulence model on CFT performance prediction, Siswantara et.al. [5] also propose that 2D is sufficient to represent the performance and flow field for pico scale proposes. Their results are summarized in Table 4.

Table 4: Relative error from experiment data of CFD results by Siswantara et.al. [5]

\begin{tabular}{lll}
\hline \multicolumn{1}{c}{ Turbulence model } & \multicolumn{1}{c}{ Average of $\boldsymbol{\delta}_{\mathbf{R}}$} & Average of $\boldsymbol{\delta}_{\mathbf{R A}}$ \\
\hline$k-\varepsilon$ & $-2.65 \%$ & $3,19 \%$ \\
RNG $k-\varepsilon$ & $-2,50 \%$ & $3,08 \%$ \\
Transitional SST & $-3,10 \%$ & $3,10 \%$ \\
\hline
\end{tabular}

From the results in Table 4, CFD results for all turbulence model has about 3\% average of $\delta_{\mathrm{R}}$ from experimental data. The difference between the error of each model is smaller than $0.11 \%$. It can be inferred that the turbulence model effect is negligible in the pico hydro CFT CFD numerical simulation. Moreover, in this result, the transitional SST model has a higher average of $\delta_{\text {RA }}$ than RNG $k-\varepsilon$ model, which contradicts prior results [5][19]. However, these studies similar found that the maximum average of $\delta_{\mathrm{RA}}$ of CFT CFD simulation using various turbulence model is below $4 \%$, which signified that all the turbulence models significantly predict the pico hydro CFT performance.

From these two results, it is recommended the $k-\varepsilon$ standard turbulent model be used for pico hydro CFT simulation because this model is lower computing power and has a simpler equation than RNG $k-\varepsilon$ and Transitional SST. However, to confirm the quality of CFD results 
using $k$ - $\varepsilon$ turbulence model, the $\mathrm{y}^{+}$value in near-wall condition should be kept in $30 \leq \mathrm{y}^{+} \leq 300$ range which is related to the meshing process [35].

\section{UNSTEADY APPROACH IN PICO HYDRO CFT NUMERICAL SIMULATION}

The CFD simulation of CFT using ANSYS Fluent software been conducted with two types of unsteady approach namely: moving mesh approach and six degrees of freedom (6-DOF) approach [36]. A comparison of the results of the two approaches can be seen in Figure 1.

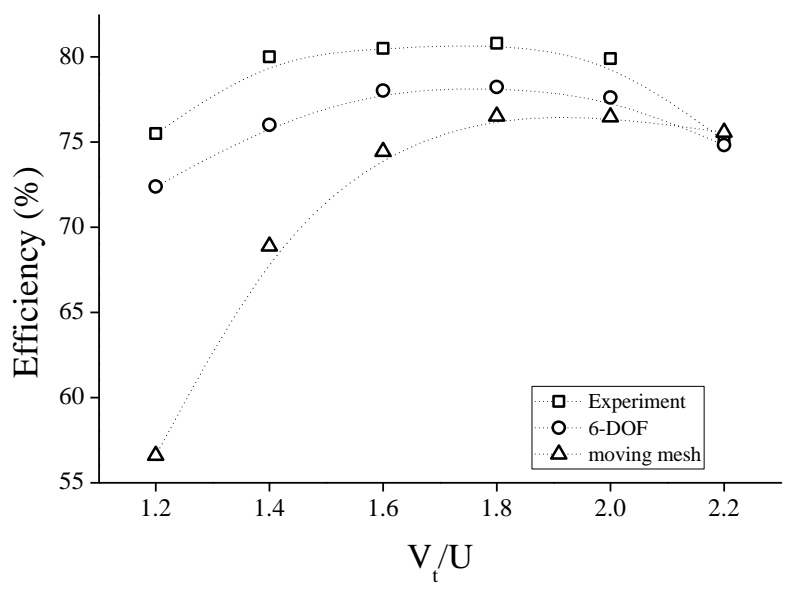

Fig. 1. CFT performance comparison between 6-DOF, moving mesh, and experiment result [36].

From Figure 1, the 6-DoF approach has closer results to experimental data than the moving mesh approach. The $\delta_{\mathrm{RA}}$ between 6-DoF and experiment result was obtained about $3.1 \%$, while the $\delta_{\text {RA }}$ of the moving mesh approach has $9.5 \%$ to experiment result [36]. It can be concluded that the 6-DoF approach is recommended to apply for pico hydro CFT CFD simulations.

\section{CONCLUSION}

The review related to CFT studies, especially on the unsteady numerical approach for CFT simulation has been conducted. The review recommended the RNG $k$ - $\varepsilon$ turbulence model for CFT 2D numerical simulation because its absolute relative error $\left(\delta_{\mathrm{RA}}\right)$ is lower than standard $k-\varepsilon$ and transitional SST, where the RNG $k-\varepsilon \delta_{\mathrm{RA}}$ of $3.08 \%$, the standard $k-\varepsilon$ of $3.19 \%$, and transitional SST of 3.10\%. For the unsteady approach, it is recommended to use 6-DoF than the moving mesh approach. Since the $6-\mathrm{DoF} \delta_{\mathrm{RA}}$ of $3.1 \%$ lower than the moving mesh of $9.5 \%$.

\section{ACKNOWLEDGEMENT}

This article was funded by Faculty of Engineering, Universitas Sriwijaya with grant no: 1981d/UN9.FT/TU.SK/2020.

\section{REFERENCES}

[1] D. Adanta, R. Hindami, Budiarso, Warjito, and A. I. Siswantara, "Blade Depth Investigation on Cross-Flow Turbine by Numerical Method," in 2018 4th International Conference on Science and Technology (ICST), 2018, pp. 1-6.

[2] S. Chichkhede, V. Verma, V. K. Gaba, and S. Bhowmick, "A Simulation Based Study of Flow Velocities across Cross Flow Turbine at Different Nozzle Openings," Procedia Technology, vol. 25, pp. 974-981, 2016. 
https://doi.org/10.51630/ijes.v2i1.11

[3] C. A. Mockmore and F. Merryfield, The Banki water-turbine, vol. 25, no. February. Engineering Experiment Station, Oregon State System of Higher Education, Oregon State College Corvallis, Ore, USA, 1949.

[4] M. Kaniecki and J. Steller, "Flow Analysis through a Reaction Cross-Flow Turbine," in Proceedings of Conference on modelling fluid flow CMFF, 2003, vol. 3, pp. 2003-2006.

[5] A. I. Siswantara, Budiarso, A. P. Prakoso, G. G. R. Gunadi, Warjito, and D. Adanta, "Assessment of Turbulence Model for Cross-Flow Pico Hydro Turbine Numerical Simulation," CFD Letters, vol. 10, pp. 38-48, 2018.

[6] D. Adanta, Budiarso, Warjito, A. I. Siswantara, and A. P. Prakoso, "Performance Comparison of NACA 6509 and 6712 on Pico Hydro Type Cross-Flow Turbine by Numerical Method," Journal of Advanced Research in Fluid Mechanics and Thermal Sciences, vol. 45, pp. 116-127, 2018.

[7] N. M. Aziz and V. R. Desai, "A Laboratory Study to Improve the Efficiency of Cross-Flow Turbines," South Caroline, 1993.

[8] J. FUKUTOMI, Y. NAKASE, and T. Watanabe, "A Numerical Method of Free Jet from a CrossFlow Turbine Nozzle," Bulletin of JSME, vol. 28, no. 241, pp. 1436-1440, 1985.

[9] V. Sammartano, C. Aricò, A. Carravetta, O. Fecarotta, and T. Tucciarelli, "Banki-Michell Optimal Design by Computational Fluid Dynamics Testing and Hydrodynamic Analysis," Energies, vol. 6, no. 5, pp. 2362-2385, 2013.

[10] N. Acharya, C.-G. Kim, B. Thapa, and Y.-H. Lee, "Numerical Analysis and Performance Enhancement of a Cross-Flow Hydro Turbine," Renewable energy, vol. 80, pp. 819-826, 2015.

[11] R. C. Adhikari and D. H. Wood, "A New Nozzle Design Methodology for High Efficiency Crossflow Hydro Turbines," Energy for Sustainable Development, vol. 41, 2017, doi: 10.1016/j.esd.2017.09.004.

[12] D. Adanta, Budiarso, Warjito, and A. I. Siswantara, "Assessment of Turbulence Modelling for Numerical Simulations into Pico Hydro Turbine," Journal of Advanced Research in Fluid Mechanics and Thermal Sciences, vol. 46, pp. 21-31, 2018.

[13] N. M. Aziz and H. G. S. Totapally, "Design Parameter Refinement for Improved Cross-Flow Turbine Performance," Engineering Report, 1994.

[14] N. H. C. Pereira and J. E. Borges, "Study of the Nozzle Flow in a Cross-Flow Turbine," International journal of mechanical sciences, vol. 38, no. 3, pp. 283-302, 1996.

[15] I. Ansys, "ANSYS FLUENT Theory Guide," Canonsburg, Pa, p. 794, 2011.

[16] Y.-D. Choi, J.-I. Lim, Y.-T. Kim, and Y.-H. Lee, "Performance and Internal Flow Characteristics of a Cross-Flow Hydro Turbine by the Shapes of Nozzle and Runner Blade," Journal of fluid science and technology, vol. 3, no. 3, pp. 398-409, 2008.

[17] J. De Andrade et al., "Numerical Investigation of the Internal Flow in a Banki Turbine," International Journal of Rotating Machinery, vol. 2011, 2011, doi: https://doi.org/10.1155/2011/841214.

[18] V. Sammartano, G. Morreale, M. Sinagra, A. Collura, and T. Tucciarelli, "Experimental Study of Cross-Flow Micro-Turbines for Aqueduct Energy Recovery," Procedia Engineering, vol. 89, pp. $540-547,2014$.

[19] V. Sammartano, G. Morreale, M. Sinagra, and T. Tucciarelli, "Numerical and Experimental Investigation of a Cross-Flow Water Turbine," Journal of Hydraulic Research, vol. 54, no. 3, pp. 321-331, 2016.

[20] R. C. Adhikari and D. H. Wood, "Computational Analysis of Part-Load Flow Control for Crossflow Hydro-Turbines," Energy for Sustainable Development, vol. 45, pp. 38-45, 2018.

[21] R. Adhikari and D. Wood, "Computational Analysis of a Double-Nozzle Crossflow Hydroturbine," Energies, vol. 11, no. 12, p. 3380, 2018.

[22] D. Adanta, R. Hindami, and A. I. Siswantara, "Blade Depth Investigation on Cross-Flow Turbine by Numerical Method," in 2018 4th International Conference on Science and Technology (ICST), 2018, pp. 1-6.

[23] D. Adanta, A. P. Prakoso, A. I. Siswantara, Warjito, and Budiarso, "Simplification Design of Nozzle and Blade of Pico Hydro Turbine Type Cross-Flow," in 17th Annual National Ceminar on Mechanical Engineering (SNTTM XVII), 2018, pp. 212-217.

[24] S. Khosrowpanah, A. A. Fiuzat, and M. L. Albertson, "Experimental Study of Cross-Flow 
Turbine," Journal of Hydraulic Engineering, vol. 114, no. 3, pp. 299-314, 1988.

[25] Maciej Kaniecki, "Modernization of the Outflow System of Cross-Flow Turbines," Task Quarterly, vol. 6, no. 4, pp. 601-608, 2002.

[26] Y. Nakase, "A Study of Cross-Flow Turbine (Effects of Nozzle Shape on Its Performance)," in ASME 103rd Winter Annual Meeting, 1982, vol. 13.

[27] W. W. Durgin and W. K. Fay, "Some Fluid Flow Characteristics of a Cross-Flow Type Hydraulic Turbine," Small Hydro Power Fluid Machinery, pp. p77-83, 1984.

[28] J. FUKUTOMI, Y. SENOO, and Y. NAKASE, "A Numerical Method of Flow through a CrossFlow Runner," JSME international journal Ser 2, Fluids engineering, heat transfer, power, combustion, thermophysical properties, vol. 34, no. 1, pp. 44-51, 1991.

[29] R. Adhikari and D. Wood, "The Design of High Efficiency Crossflow Hydro Turbines: A Review and Extension," Energies, vol. 11, no. 2, p. 267, 2018, doi: https://doi.org/10.3390/en11020267.

[30] H. K. H. K. Versteeg and W. Malalasekera, An introduction to computational fluid dynamics: the finite volume method. Pearson Education, 2007.

[31] Y. D. Choi, J. I. Lim, C. G. Kim, Y. T. Kim, and Y. H. Lee, "CFD Analysis for the Performance of Cross-Flow Hydraulic Turbine with the Variation of Blade Angle," in New Trends in Fluid Mechanics Research, Springer, 2007, pp. 428-431.

[32] Y.-D. Choi, J.-I. Lim, Y.-T. Kim, and Y.-H. Lee, "Internal Flow Characteristics of Cross-Flow Hydraulic Turbine with the Variation of Nozzle Shape," in ASME/JSME 2007 5th Joint Fluids Engineering Conference, 2007, pp. 1089-1094.

[33] M. Sinagra, V. Sammartano, C. Aricò, A. Collura, and T. Tucciarelli, "Cross-Flow Turbine Design for Variable Operating Conditions," Procedia Engineering, vol. 70, pp. 1539-1548, 2014.

[34] V. Sammartano, C. Aricò, M. Sinagra, and T. Tucciarelli, "Cross-Flow Turbine Design for Energy Production and Discharge Regulation," Journal of Hydraulic Engineering, vol. 141, no. 3, 2015, doi: 10.1061/(ASCE)HY.1943-7900.0000977.

[35] A. Fluent, "ANSYS Fluent Theory Guide 15.0," ANSYS, Canonsburg, PA, 2013.

[36] A. P. Prakoso, Warjito, A. I. Siswantara, Budiarso, and D. Adanta, "Comparison Between 6-DOF UDF and Moving Mesh Approaches in CFD Methods for Predicting Cross-Flow Pico- Hydro Turbine Performance," CFD Letters, vol. 11, no. 6, pp. 86-96, 2019. 